Abstract 9 Table 2 VAS pain scores of the arm at rest and in abduction

\begin{tabular}{|c|c|c|c|c|}
\hline $\begin{array}{l}\text { VAS scores at } \\
\text { rest }\end{array}$ & $\begin{array}{c}\text { Group PECS } \\
(n=30)\end{array}$ & $\begin{array}{c}\text { Group ESP } \\
(n=30)\end{array}$ & $\begin{array}{l}\text { Group Control } \\
(\mathbf{n}=\mathbf{3 0})\end{array}$ & $p^{*}$ \\
\hline $1 \mathrm{~h}$ & $\begin{array}{l}3,3 \pm 1,8 \\
3^{a}(2-4)\end{array}$ & $\begin{array}{c}4,3 \pm 1,5 \\
5^{b}(3-5)\end{array}$ & $\begin{array}{l}5,9 \pm 1,5 \\
\sigma^{c}(5-7)\end{array}$ & $<0,001$ \\
\hline $3 \mathrm{~h}$ & $\begin{array}{c}3,1=1,2 \\
3^{\mathrm{a}}(2-4)\end{array}$ & $\begin{array}{c}3,4 \pm 1,2 \\
4^{\mathrm{a}}(2-4)\end{array}$ & $\begin{array}{c}5,1 \pm 1,4 \\
5^{b}(4-6)\end{array}$ & $<0,001$ \\
\hline $6 \mathrm{~h}$ & $\begin{array}{c}2,3=0,9 \\
2^{2}(2-3)\end{array}$ & $\begin{array}{l}2,8 \pm 1,3 \\
3^{2}(2-3)\end{array}$ & $\begin{array}{c}3,9=1,1 \\
4^{b}(3-5)\end{array}$ & $<0,001$ \\
\hline $12 \mathrm{~h}$ & $\begin{array}{l}1,6=0,8 \\
2^{2}(1-2)\end{array}$ & $\begin{array}{c}2,0=1,0 \\
2^{\mathbf{a}}(1-3)\end{array}$ & $\begin{array}{c}3,0=1,1 \\
3^{b}(2-4)\end{array}$ & $<0,001$ \\
\hline $24 \mathrm{~h}$ & $\begin{array}{c}1,1=0,6 \\
1^{2}(1-1)\end{array}$ & $\begin{array}{c}1,2=0,6 \\
1^{\mathrm{a}}(1-1)\end{array}$ & $\begin{array}{l}1,9=1,1 \\
2^{b}(1-2)\end{array}$ & 0,002 \\
\hline 3 month & $\begin{array}{c}0,1=0,3 \\
0^{2}(0-0)\end{array}$ & $\begin{array}{l}0,0=0,2 \\
0^{2}(0-0)\end{array}$ & $\begin{array}{c}0,4=0,6 \\
0^{b}(0-1)\end{array}$ & 0.008 \\
\hline \multicolumn{5}{|l|}{$\begin{array}{l}\text { VAS scores in } \\
\text { abduction }\end{array}$} \\
\hline $1 \mathrm{~h}$ & $\begin{array}{l}4,8 \pm 1,6 \\
5^{\mathrm{a}}(4-5)\end{array}$ & $\begin{array}{l}5,8 \pm 1,7 \\
6^{\mathrm{a}}(5-7)\end{array}$ & $\begin{array}{l}7,4 \pm 1,4 \\
8^{b}(7-8)\end{array}$ & $<0,001$ \\
\hline $3 \mathrm{~h}$ & $\begin{array}{c}4,7 \pm 1,4 \\
5^{\mathrm{a}}(4-5)\end{array}$ & $\begin{array}{l}4,9 \pm 1,6 \\
5^{\mathrm{a}}(4-6)\end{array}$ & $\begin{array}{l}6,5 \pm 1,5 \\
7 b(6-8)\end{array}$ & $<0,001$ \\
\hline $6 \mathrm{~h}$ & $\begin{array}{c}3,8 \pm 1,4 \\
4^{\mathrm{a}}(2-5)\end{array}$ & $\begin{array}{l}4,4 \pm 1,7 \\
5^{\mathrm{a}}(3-6)\end{array}$ & $\begin{array}{c}5,8 \pm 1,3 \\
6^{\mathrm{b}}(5-7)\end{array}$ & $<0,001$ \\
\hline $12 \mathrm{~h}$ & $\begin{array}{l}3,1 \pm 1,5 \\
4^{\mathrm{a}}(2-4) \\
\end{array}$ & $\begin{array}{c}3,5 \pm 1,5 \\
4^{\mathrm{a}}(2-5) \\
\end{array}$ & $\begin{array}{c}4,6 \pm 1,1 \\
5^{b}(4-5)\end{array}$ & $<0,001$ \\
\hline $24 \mathrm{~h}$ & $\begin{array}{c}2,4 \pm 1,1 \\
3^{\mathrm{a}}(1-3)\end{array}$ & $\begin{array}{l}2,6 \pm 1,3 \\
2^{2}(1-4) \\
\end{array}$ & $\begin{array}{c}3,7 \pm 1,6 \\
4^{b}(2-5)\end{array}$ & 0,001 \\
\hline 3 month & $\begin{array}{c}0,2 \pm 0,4 \\
0^{\mathrm{a}}(0-0)\end{array}$ & $\begin{array}{c}0,3 \pm 0,5 \\
0^{\mathrm{s}}(0-1)\end{array}$ & $\begin{array}{c}0,8 \pm 0,6 \\
1^{\mathrm{b}}(0-1)\end{array}$ & $<0,001$ \\
\hline
\end{tabular}

analogue scale (VAS) pain scores of the arm at rest and in abduction at hours $1,3,6,9,12$, and 24 . In addition, the VAS pain scores in the third month following discharge were asked to evaluate the development of chronic pain.

Results Both VAS scores, intraoperative remifentanil consumption, and postoperative 24-hour morphine consumption were lower in the ESP and PECS groups compared with the control group. The time to first request for analgesia via PCA was longer in the groups performed block compared with the control group. While the time to onset of block was found to be shorter in the PECS group, none of the patients needed rescue analgesia.

Conclusions The study demonstrated that the US-guided ESP and PECS block performed in patients who underwent breast cancer surgery provided effective analgesia for acute and chronic pain.

\section{SPONTANEUS REDUCTION OF ANALGESICS AFTER INTERVENTIONAL TECHNIQUE FOR LUMBAR CHRONIC PAIN, AS A MARKER OF IT'S EFFECTIVENESS}

I Fuertes-Arenal*, P Lejarraga, R Vela-Pascual, L Velasco, S Garcia-Hernandez, F HigueroCantonero, F De la Gala Garcia, A Alonso Chico, S Zapatero García, J Blanco Aceituno, E Lopez Perez, J Aguilar Godoy. Hospital General Universitario Gregorio Marañon, Madrid, Spain

\subsection{6/rapm-2021-ESRA.10}

Background and Aims Interventional techniques for chronic lumbar Pain Release (ITPR) are widely performed but there's little evidence about how to assess its success. The aim of this study is to assess if quitting or reducing analgesics one month after an ITPR is useful as an objective measure of its success. Methods 251 adult patients were included in this observational prospective study.Pain intensity (numeric rating score) and disability (Oswestry scale) were assessed via telephone before ITPR, and 1 month later. In addition, analgesics cessation or dose reduction was asked.

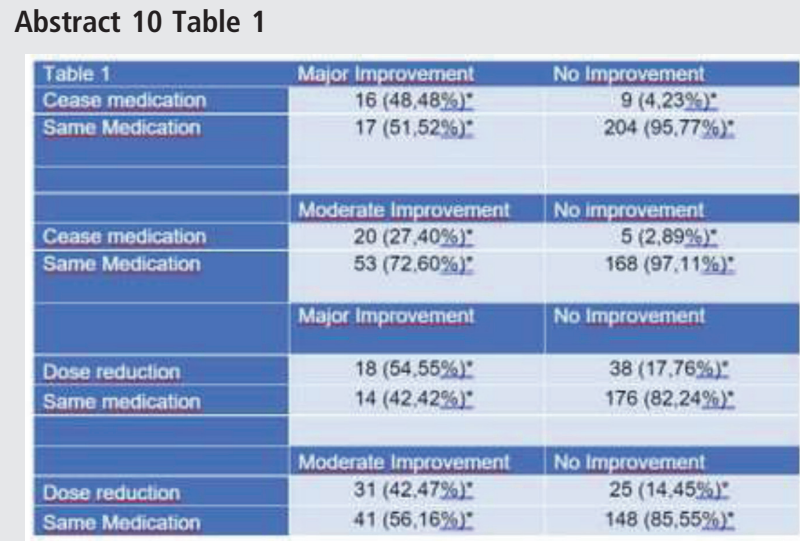

Percentages are ceferred to total of each selumn

As success we considered major improvement when a 3 point in NRS and a 40\% in Oswestry reduction was reported. Moderate improvement was considered to be a 2 point reduction and a $20 \%$ respectively. If either criteria were met, no improvement was assessed.

We calculated sensitivity, specifity, and predictive values of quitting or reducing medication, for each success criteria.

Results Number/percentage of patients meeting each criteria are shown in table no. 1

Cease of medication showed a $95 \%$ and $97 \%$ specifity for major and moderate improvement. Sensibility was $48 \%$ and $27 \%$. PPV was $64 \%$ and $80 \%$. NPV was $92 \%$ and $76 \%$ respectively.

Dose reduction showed an $82 \%$ and $85 \%$ specifity for major and minor improvement, and $56 \%$ and $43 \%$ sensibility. PPV was 32\% and 55\%. NPV was 92 and 78\%.

Conclusions $48,5 \%$ of those who had major improvement with an ITPR quitted spontaneously at least one analgesic of its daily medication. Also, it showed an 92,3\% NPV and $64 \%$ PPV. Prevalence of major improvement was $13 \%$.

\section{Case report}

\section{ASYMPTOMATIC CEREBROSPINAL FLUID FISTULA FOLLOWING COMBINED SPINAL-EPIDURAL ANAESTHESIA IN A HEALTHY PARTURIENT}

RF Santos, RL Silva*, J Rego, F Moura. Centro Hospitalar Tâmega e Sousa, Guilhufe, Penafiel, Portugal

\subsection{6/rapm-2021-ESRA.11}

Background and Aims Cerebrospinal fluid (CSF) cutaneous fistula is a rare complication that can occur after a neuraxial anaesthesia technique. It can cause serious complications such as incapacitating headaches, cranial nerve symptoms, central nervous system infection and intracranial subdural hematoma. ${ }^{1}$ Methods Description of a case report in the section below.

Results Case report: A healthy pregnant woman was subjected to a c-section after an uneventful combined spinal-epidural neuraxial block. On the second postoperative day, upon the removal of the epidural catheter, a fluid leakage was noticed emerging from the puncture site. The fluid was crystalline and had a measured glucose level of $83 \mathrm{mg} / \mathrm{dL}$. The patient was completely asymptomatic. Following neurosurgery consultation, 
the leak site was sutured at the skin level after $24 \mathrm{~h}$ of persistent leakage. The patient was discharged home the next day completely asymptomatic. She had the suture removed 3 days later, without any recurrence of the leakage. She didn't report any symptoms during a two-month follow-up.

Conclusions This report presents another case of a CSF fistula after a neuraxial block and highlights the success of a conservative approach that avoided not only a blood patch, but also a surgical procedure, in an asymptomatic young woman.

\section{FLUOROSCOPIC APPROACH TO NEURAXIAL ANAESTHESIA IN A PATIENT OF KYPHOSCOLIOSIS}

S Gupta*, R Mane. Jawaharlal Nehru Medical College, KAHER, Belagavi, India

\subsection{6/rapm-2021-ESRA.12}

Background and Aims Kyphoscoliosis is a complex deformity of the spine resulting in lateral curvature and rotation of the vertebrae and a deformity of the rib cage. There is usually secondary involvement of the cardio-respiratory and neurologic systems.

Neuraxial block is routinely performed without the aid of imaging modalities and approached blindly for placement of epidural catheter. Kyphoscoliosis poses a remarkable challenge to administration of neuraxial anaesthesia and may result in multiple pricks and complications such as nerve injury and hematoma formation.

We aimed to assess the feasibility and success of using fluoroscopy guidance for administration of epidural anaesthesia in a case of severe kyphoscoliosis.

Methods A 18-year-old female $132 \mathrm{~cm}$ tall, with severe kyphoscoliosis was posted for Cholecystectomy. She had severe dextrorotatory-thoracic scoliosis [Cobb angle- $62^{\circ}$ ] and a compensatory levorotatory-lumbar curve $\left[45^{\circ}\right]$. Respiratory examination showed restricted breathing with $\mathrm{B} / \mathrm{L}$ wheeze. PFT showed a restrictive pattern. Open cholecystectomy was planned under Epidural Anaesthesia. Serial MRI films were assessed to determine the direction of placement of the epidural needle which was enhanced with the use of fluroscopy guidance during the intraoperative period.

Results Intraoperative period assessed in terms of patient compliance and adequate surgical anaesthesia was satisfactory.

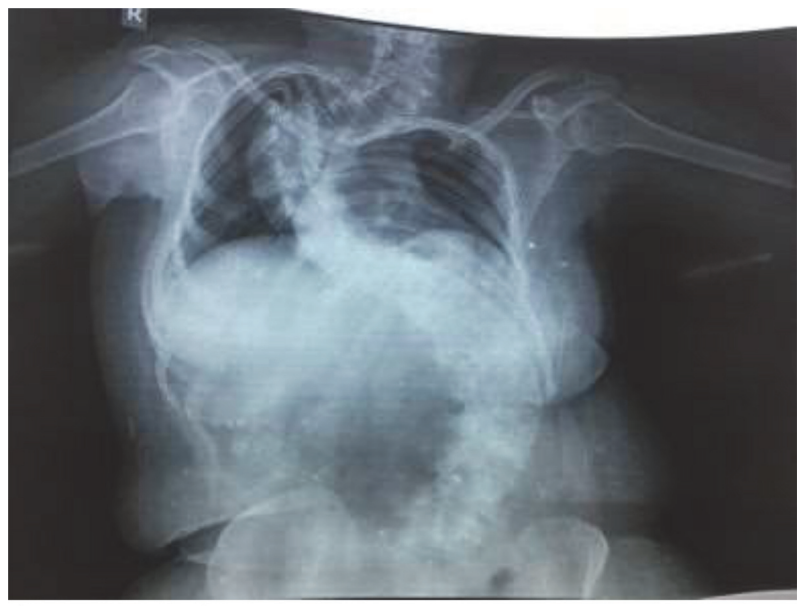

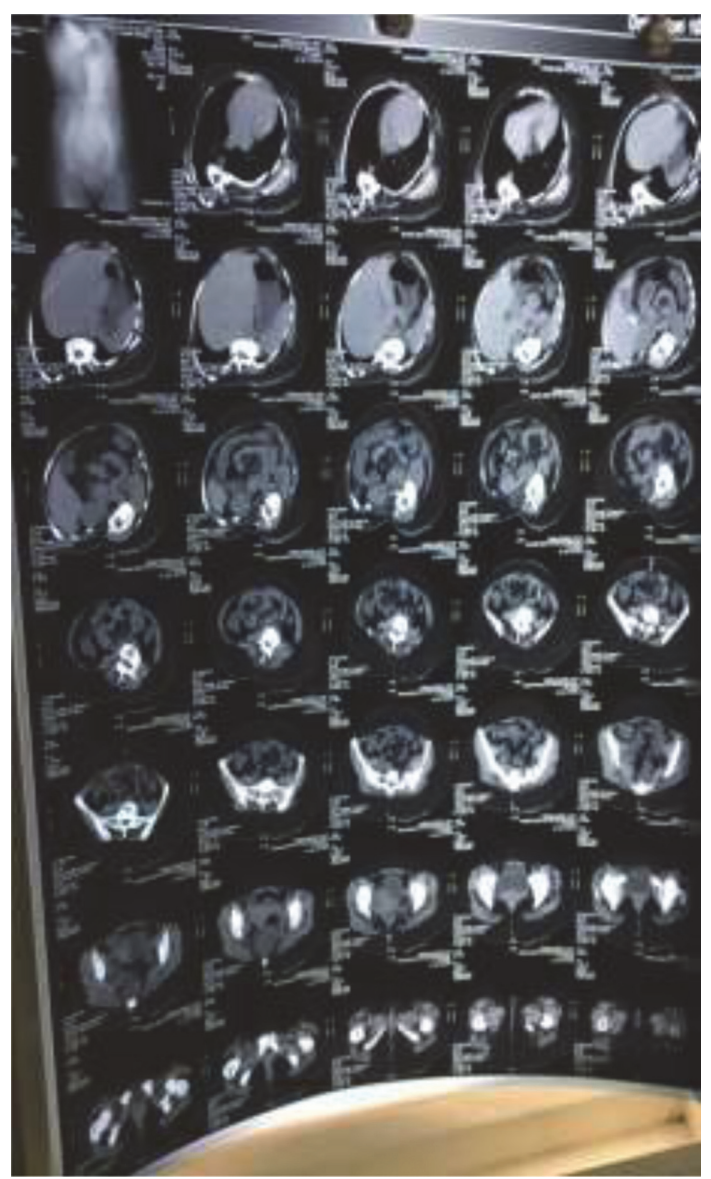

Abstract 12 Figure 2

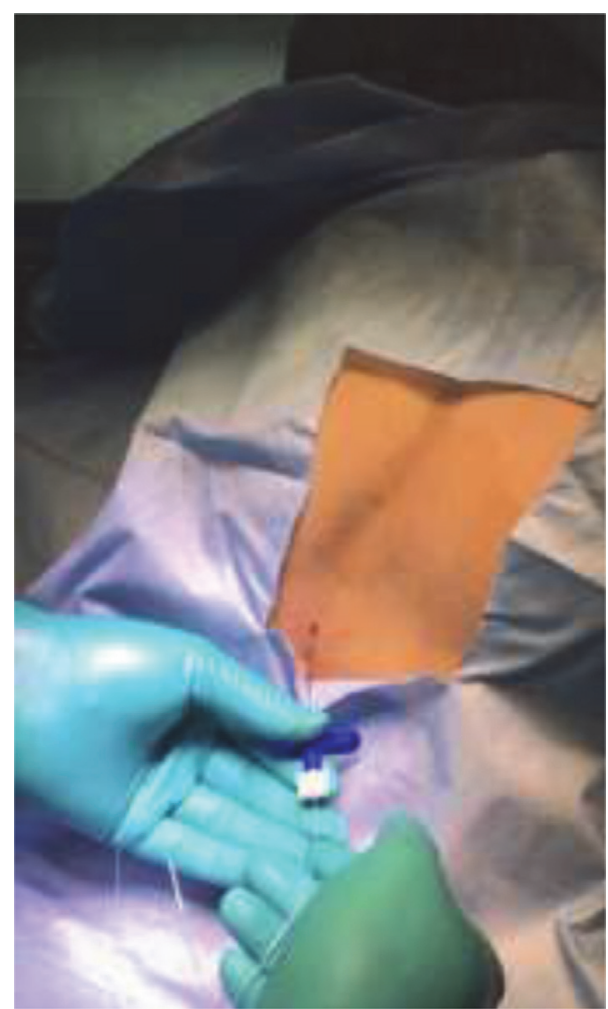

Abstract 12 Figure 3 